\title{
Transmucosal potential difference; diagnostic value in gastro-oseophageal reflux
}

\author{
B. KHAMIS, ${ }^{1}$ C. KENNEDY, J. FINUCANE, AND J. STEPHEN DOYLE, 2 \\ From the Department of Medicine, Royal College of Surgeons in Ireland, Dublin, and the Departments of \\ Medicine and Pathology, St. Laurence's (Richmond) Hospital, Dublin
}

SUMMARY Nineteen patients with symptoms of upper gastrointestinal disease were assessed by endoscopy. Transmucosal potential difference(PD) in the lower oesophagus was recorded and suction biopsy specimens were obtained from the site of measurement and examined by light microscopy after haematoxylin and eosin staining. In 10 patients with normal histology, mean PD was $-14.4 \mathrm{mV}$ $(\mathrm{SEM} \pm 0.4 \mathrm{mV})$, whereas in nine patients with histological changes of reflux mean was $+9.4 \mathrm{mV}$ $(\mathrm{SEM} \pm 3.0 \mathrm{mV})$. In this latter group, polarity of the PD was reversed in all but one case. Good correlation was found between these objective indices of lower oesophageal disease and the presence of symptoms such as dysphagia and heartburn. The visual appearance at endoscopy was less reliable. It is suggested that measurement of PD is a simple, rapid, and sensitive method of detecting the presence of oesophageal mucosal damage.

The existence in man of an electrical potential difference between the mucosal and serosal surface of the upper gastrointestinal tract has long been recognised (Swyngedauw, 1928). It has been suggested (Geall et al., 1970) that this potential difference reflects mucosal integrity. Disruption of the gastric mucosal 'barrier' is associated with a fall in transmucosal potential difference (Davenport, 1968; Black et al., 1971). Relatively few studies of oesophageal transmucosal potential difference have been reported. Helm et al. (1965) utilised transmucosal potential difference to identify the gastrooesophageal junction but the technique employed by these workers did not ensure adequate contact between the exploring electrode and mucosal surface. Accurate placement of an exploring electrode under direct vision at endoscopy was described by Cochran and Russell (1973). We have applied this technique to measure transmucosal potential difference in the lower oesophagus. Recorded values were correlated with the histological appearance of mucosal biopsy specimens taken from the area of contact with the exploring electrode. Visual appearance at endoscopy was noted and recorded by an experienced observer. (J.S.D.)

${ }^{1}$ Supported by a grant from the Medical Research Council of Ireland.

'Address for reprint requests: Professor J. Stephen Doyle, Department of Medicine, RCSI, Professional Unit, RCSI, St. Laurence's Hospital, Dublin 7.

Received for publication 16 January 1978

\section{Methods}

\section{PATIENTS}

A total of 19 patients (nine female and 10 male) were studied. Mean age was 47 years (range 28-72 years). All had been referred to the Department of Gastroenterology at St. Laurence's Hospital because of upper gastrointestinal symptoms such as dysphagia, heartburn, retrosternal discomfort, and epigastric pain. Measurements of transmucosal potential difference were carried out in conjunction with standard upper gastrointestinal endoscopy and biopsy procedures which form part of the routine investigations of such patients in this department. Informed consent was obtained in every case.

Fasting patients were given atropine $0.6 \mathrm{mg}$ and pethidine $75 \mathrm{mg}$ intramuscularly one hour before examination. Immediately beforehand, the pharynx was sprayed with $1 \%$ xylocaine, after which hyoscine butylbromide $20 \mathrm{mg}$ together with sufficient diazepam (usually $<10 \mathrm{mg}$ ) to produce ptosis and slurring of speech was injected intravenously. Transmucosal potential difference was measured by a modification (Khamis et al., 1977) of the method of Andersson and Grossman (1965). Electrodes consisted of polyvinyl tubing (PPE 190; external diameter $2 \mathrm{~mm}$ ) filled with saturated potassium chloride in 3\% agar gel leading to two beakers containing saturated potassium chloride solution and a Beckman calomel half-cell. The two Beckman 
calomel half-cells were connected to a battery operated digital voltmeter (Sinclair Multivoltmeter) which gave a digital readout of the potential difference with polarity. The exploring mucosal electrode was passed through the biopsy forceps channel of the endoscope (Olympus GIF-D2). The reference electrode was placed on the unprepared volar surface of the right supinated forearm, $10 \mathrm{~cm}$ below the antecubital fossa. Good contact for the latter electrode was ensured by packing the tip with cotton wool soaked in saturated potassium chloride solution. The area of contact between skin and cotton wool was approximately $1 \mathrm{~cm}^{2}$ and was maintained by light pressure. Preliminary experiments had shown that the use of such a reference electrode virtually abolished skin potential. Thus, in a series of 10 experiments in three subjects, measured transmucosal potential difference was no greater than $3 \mathrm{mV}$ more negative when the reference electrode was placed intravenously.

Transmucosal potential difference was recorded at the lower end of the oesophagus at least $5 \mathrm{~cm}$ above the mucosal oesophagogastric junction (identified at endoscopy) by placing the exploring electrode firmly against the mucosa under direct vision. When potential difference had been recorded, the electrode was withdrawn. Biopsies were taken from the site with a crocodile forceps (Olympus biopsy forceps with needle). Suction biopsies (Rubin tube) were also taken from the same level when the endoscope had been removed. Biopsy specimens were preserved in formalin and subsequently examined under a light microscope after staining with haematoxylin and eosin. Specimens were classified histologically according to the criteria laid down by Ismail-Beigi et al. (1970), by a colleague (C.K.) who had no knowledge of the endoscopic appearance or measured transmucosal potential difference. Specimens obtained by crocodile forceps biopsy were adequate for such classification.
Results

Nine patients $(47 \%)$ fulfilled the histological criteria for reflux changes (basal cell hyperplasia, location of papillae close to epithelial surface). In 10 cases $(53 \%)$ normal histology was reported. Individual values for measured transmucosal potential difference are shown in the Table. In patients whose biopsy specimens were normal, the mean value (mucosa electronegative in respect of skin) was $-14.4 \mathrm{mV}$ (range -13 to $-16 \mathrm{mV}$; SEM $\pm 0.4 \mathrm{mV}$ ), whereas, in those with histological abnormalities, a mean value of $+9.4 \mathrm{mV}$ (range -4 to $+24 \mathrm{mV}$; SEM $\pm 3.0 \mathrm{mV}$ ) was recorded. In all but one patient in the latter group, polarity was reversed. There is a highly significant $(P<0.001)$ correlation between transmucosal potential difference and histological appearance. Eight out of nine patients with abnormal histology had symptoms suggestive of oesophageal disease (dysphagia, acid reflux, retrosternal pain), whereas only one of 10 patients with a normal biopsy volunteered such symptoms. All patients in the latter group had presented with epigastric pain with or without nausea or vomiting.

The naked eye appearance of the oesophagus at endoscopy correlated poorly both with the microscopic appearance of biopsy specimens and measured potential difference. A normal appearance was reported in five out of nine patients subsequently shown to have abnormal histology, whereas naked eye pathological features were thought to be present in two cases with normal biopsy.

\section{Discussion}

The physiological basis of transmucosal potential difference has not been fully defined but is believed to be a function of ionic flux at mucosal level

Table Data from patients with normal and abnormal lower oesophageal histology

\begin{tabular}{|c|c|c|c|c|c|}
\hline \multicolumn{3}{|c|}{ Normal Biopsies } & \multicolumn{3}{|c|}{ Reflux change } \\
\hline$P D m V$ & Oesophageal symptoms & Endoscopic appearance & $P D m V$ & Oesophageal symptoms & Endoscopic appearance \\
\hline $\begin{array}{l}-13 \\
-13 \\
-16 \\
-14 \\
-14 \\
-15 \\
-13 \\
-16 \\
-14 \\
-16 \\
n=10 \\
-14 \cdot 4 \pm\end{array}$ & $\begin{array}{l}- \\
\overline{-} \\
\overline{-} \\
+ \\
\overline{-} \\
\overline{-} \\
\text { ean } \pm \text { SEM) }\end{array}$ & $\begin{array}{l}\text { Normal } \\
\text { Normal } \\
\text { Normal } \\
\text { Normal } \\
\text { Oesophagitis } \\
\text { Normal } \\
\text { Normal } \\
\text { Normal } \\
\text { Oesophagitis } \\
\text { Normal }\end{array}$ & $\begin{array}{l}+11 \\
+1 \\
+1 \\
+24 \\
+9 \\
+9 \\
+4 \\
+15 \\
+19 \\
n=9 \\
+9.4 \pm 3\end{array}$ & $\begin{array}{l}+ \\
+ \\
- \\
+ \\
+ \\
+ \\
+ \\
+ \\
+\end{array}$ & $\begin{array}{l}\text { Normal } \\
\text { Oesophagitis/mass } \\
\text { Normal } \\
\text { Oesophagitis/reflux } \\
\text { Oesophagitis/peptic } \\
\text { stricture } \\
\text { Normal } \\
\text { Normal } \\
\text { Normal } \\
\text { Oesophagitis }\end{array}$ \\
\hline
\end{tabular}


(Forte et al., 1963). Furthermore, methods of measurement are of somewhat arbitrary design. Helm et al. (1965) have reported that in the oesophagus, unlike the stomach, the mucosal surface is electropositive in regard to the serosal surface. However, values reported in the 'normal' subjects studied by us are very similar (in polarity and magnitude) to those found by Andersson and Grossman (1965) who used an intravenous reference electrode.The same authors reported that transmucosal potential difference is approximately $30 \mathrm{mV}$ more positive when a finger dipped in electrolyte solution is employed as reference electrode. Our preliminary experiments suggest that skin potential is virtually abolished when the reference electrode is sited on the thin skin of the volar forearm surface and an adequate area of contact is ensured.

We have found an extremely good correlation between the histological changes considered by Ismail-Beigi et al. (1970) to be characteristic of reflux and abnormalities of oesophageal transmucosal potential difference. In all but one case a reversal of normal polarity was seen. Good correlation was also apparent between these objective indices and the presence of symptoms suggestive of lower oesophageal dysfunction, this underlines the value of careful history taking and of questioning the patient specifically about the presence of heartburn, dysphagia, and retrosternal discomfort. The visual appearance of the oesophagus at endoscopy is clearly less reliable in the diagnosis of oesophageal disease. Other workers have evaluated the usefulness of transmucosal potential difference in assessing oesophageal mucosal integrity. Vidins et al. (1971) demonstrated clear abnormalities in patients with a variety of oesophageal pathology. Alterations in potential difference opposite in direction to those reported here were found by Beck and Hernandez (1969) in a group of patients with oesophageal ulceration. However, the pullthrough technique employed by these workers is liable to technical error because of poor contact between the mucosa and exploring electrode. Neither of these groups combined endoscopic and histological appearances with measurement of potential difference in the manner of the present study.
Measurement of lower oesophageal transmucosal potential difference under direct vision at endoscopy is a simple, rapid, and accurate method for diagnosis of reflux-induced oesophageal mucosal damage and may well be of value in the routine assessment of patients with upper gastrointestinal symptoms. It may also prove useful in differentiating between symptoms arising from the oesophagus and those of cardiac origin.

\section{References}

Andersson, S., and Grossman, M. I. (1965). Profile of pH pressure, and potential difference at gastroduodenal junction in man. Gastroenterology, 49, 364-371.

Beck, I. T., and Hernandez, N. A. (1969). Transmucosal potential difference in patients with hiatus hernia and oesophageal ulcer. Gut, 10, 469-476.

Black, R. B., Hole, D., and Rhodes, J. (1971). Bile damage to the gastric mucosal barrier: the influence of $\mathrm{pH}$ and bile acid concentration. Gastroenterology, 61, 178-184.

Cochran, K. M., and Russell, R. I. (1973). The measurement of gastric transmucosal potential difference through a gastroduodenoscope. Gut, 14, 903-904.

Davenport, H. W. (1968). Destruction of the gastric mucosal barrier by detergents and urea. Gastroenterology, 54, 175181.

Forte, J. G., Adams, P. H., and Davies, R. E. (1963). Source of the gastric mucosal potential difference. Nature, 197, 874-876.

Geall, M. G., Phillips, S. F., and Summerskill, W. H. J. (1970). Profile of gastric potential difference in man; effects of aspirin, alcohol, bile, and endogenous acid. Gastroenterology, 58, 437-443.

Helm, W. J., Schlegel, J. F., Code, C. F., and Summerskill, W. H. J. (1965). Indentification of the gastrooesophageal mucosal junction by transmucosal potential in healthy subjects and patients with hiatal hernia. Gastroenterology, 48, 25-35.

Ismail-Beigi, F., Horten, P. F., and Pope, C. E., (1970). Histological consequences of gastrooesophageal reflux in man. Gastroenterology, 58, 163-174.

Khamis, B., Finucane, J., and Doyle, J. S. (1977). The effect of oral cimetidine on $\mathrm{pH}$ and gastric transmucosal potential difference in canine Heidenhain pouches (abstract). Irish Journal of Medical Science, 146, 86.

Swyngedauw, J. (1928). Sur l'existence d'une différence de potentiel variable entre la bouche et l'estomac au cours de la sécrétion gastrique. Compte Rendus de Séances de la Société de Biologie, 98, 1431-1432.

Vidins, E. I., Fox, J. A. E., and Beck, I. T. (1971). Transmucosal potential difference (P.D.) in the body of the esophagus in patients with esophagitis, Barrett's epithelium and carcinoma of the esophagus. American Journal of Digestive Diseases, 16, 991-999. 